\title{
Agências irmãs? Semelhanças e diferenças na institucionalização via mudança institucional das ouvidorias da ANTT e da Antaq
}

Luciana de Oliveira Miranda

Universidade de Brasília (UnB)

Paulo Du Pin Calmon

Universidade de Brasília (UnB)

Este artigo discute como ocorreram os processos e mecanismos de mudança institucional na institucionalização de ouvidorias públicas, da sua criação até o ano de 2013. A pesquisa foi desenvolvida com estudos de caso na Agência Nacional de Transportes Aquaviários (Antaq) e na Agência Nacional de Transportes Terrestres (ANTT). A coleta de dados foi feita em três fases: pesquisa bibliográfica, documental e entrevistas. A análise dos dados fundamentouse na análise documental, dado o grande volume de documentos oficiais e das entrevistas transformadas em texto, e análise de conteúdo. O modelo analítico utilizado inclui uma proposta inédita de utilização da Teoria da Mudança Institucional na análise dos processos de institucionalização. O modelo proposto permitiu observar evidências de ações de criação e desmantelamento de instituições nas respectivas ouvidorias. De fato, observou-se que uma mesma lei de criação das agências não influiu para que ambas fossem institucionalizadas da mesma maneira. Tem maior influência o desempenho de empreendedores institucionais quando encaram ante si um espaço de negociação para reinterpretação das regras atuais definidas pelos governos criadores dessas organizações.

Palavras-chave: ouvidoria pública, institucionalização, mudança organizacional, estudo de caso

¿Agencias Hermanas? Similitudes y diferencias en la institucionalización a través de cambio institucional del defensor del pueblo de ANTT y Antaq

Este artículo describe cómo ocurrió procesos y mecanismos institucionales de cambio en la institucionalización del Defensores del Pueblo, de su creación hasta el año 2013. La investigación se desarrolló con estudios de caso de la Agencia Nacional de Transporte Fluvial (Antaq) y la Agencia Nacional de Transportes in Tierra (ANTT). La recolección de datos se

[Artigo submetido em 2 de setembro de 2015. Aprovado em 7 de abril de 2017.] 
llevó a cabo en tres fases: la revisión de literatura, documentales oficiales y entrevistas. Análisis de los datos se basó en el análisis de documentos, ya que el volumen de documentos oficiales y las entrevistas se convirtió en el texto, y el análisis de contenido. El modelo analítico utilizado incluye una propuesta sin precedentes para utilizar la Teoría de Cambio Institucional en el análisis de los procesos de institucionalización. El modelo propuesto nos permitió observar evidencias de cría y el desmantelamiento de las instituciones del Defensor del Pueblo correspondiente. De hecho, se observa que la misma ley de creación de organismos no influye de modo que ambos están institucionalizados de la misma manera, pero el rendimiento de los empresarios institucionales cuando se enfrentan ante ellos una sala de operaciones para la reinterpretación de las normas vigentes establecidas por los creadores de los gobiernos de estas organizaciones.

Palabras clave: defensor del pueblo, institucionalización, cambio organizacional, estudio de caso

\section{Twin Agencies? Similarities and Differences in Institutionalization through Institutional} Change of ANTT and Antaq Ombudsman's Offices

This paper discusses how occurred the processes and mechanisms of institutional change in the institutionalization of public ombudsmen, since their creation until the year of 2013. The research was developed with case studies at the National Agency of Waterway Transportation (Antaq) and at the National Land Transportation Agency (ANTT). Data collection was done in three phases: literature, documentary and interviews. Data analysis was based on document analysis, as the sheer volume of official documents and the interviews turned into text, and content analysis. The analytical model used includes an unprecedented proposal to use the Institutional Change Theory in the analysis of institutionalization processes. The proposed model allowed us to observe evidence of creation and dismantling institutions at respective public ombudsmen. In fact, it is observed that the same law of creation of agencies does not influence so that both are institutionalized in the same way, but the performance of institutional entrepreneurs when faced before them a trading room for reinterpretation of the current rules established by the creators' governments of these organizations.

Keywords: public ombudsman, institutionalization, organizational change, case study 


\section{Introdução}

O objetivo deste artigo é compreender, a partir do espaço de investigação escolhido - duas agências reguladoras federais -, como ocorrem os processos e os mecanismos de mudança institucional (MAHONEY; THELEN, 2010) na institucionalização - criação, manutenção ou desmembramento (LAWRENCE; SUDDABY, 2006) - das ouvidorias dessas mesmas agências, por meio da investigação do comportamento dos principais atores responsáveis por processos de mudança frente às possíveis ações de criação, desenvolvimento e desmantelamento de instituições.

Com o intuito de responder a esse questionamento, o artigo foi estruturado e desenvolvido com estudos de caso (STAKE, 2000), nas ouvidorias de duas agências: Agência Nacional de Transportes Aquaviários (Antaq) e Agência Nacional de Transportes Terrestres (ANTT). O processo de coleta de dados foi feito em três fases interligadas, por meio de pesquisa bibliográfica, pesquisa documental e entrevistas semiestruturadas. A análise dos dados fundamentou-se na análise documental (CELLARD, 2008), dado o grande volume de documentos oficiais e das entrevistas transformadas em texto, e análise de conteúdo (APPOLINÁRIO, 2009).

A despeito das produções acadêmicas que surgem desde a implantação da primeira agência reguladora federal, em 1999, e, consequentemente, a organização de sua ouvidoria, o foco dessas investigações baseou-se em aspectos legais, estruturais e de reflexão acerca do papel desse novo setor - a ouvidoria pública - dentro da administração pública do País, e o que o usuário-cidadão percebia do novo setor. Não foi localizada uma pesquisa que se propusesse a entender o processo de construção da ouvidoria a partir dos próprios atores envolvidos, e como esses se comportavam. Ou seja, que adotasse um olhar de dentro para fora do órgão ouvidoria.

O modelo analítico utilizado parte do tema institucionalização. Esse, apesar de não ser novo, inclui uma proposta de utilização da Teoria da Mudança Institucional (MAHONEY; THELEN, 2010) na análise dos processos de institucionalização das ouvidorias públicas das agências reguladoras federais, proposta essa ainda inédita. Assim, o artigo apresenta os resultados suscitados pela aplicação do modelo de mudança institucional de Mahoney e Thelen (2010), conjugado com a contribuição de Lawrence e Suddaby (2006), na institucionalização das ouvidorias das duas agências reguladoras federais analisadas. A discussão dos resultados é feita a seguir, quando se apresentam, em primeiro lugar, as implicações de cada caso, para depois exercitar possíveis comparações e conclusões. 


\section{Processos de institucionalização}

Instituições são o conjunto de regras e normas, formais e informais, que enquadram e regulam as interações entre indivíduos e organizações. Em função disso, poderíamos supor que elas podem ser criadas e manipuladas intencionalmente, com objetivo de estabelecer comportamentos e viabilizar a consecução de determinados objetivos organizacionais ou políticos. Nesse sentido, o estabelecimento e a modificação das instituições seguiriam o que March (2009) cognominou de a "lógica das consequências". Mas em que medida o processo de mudança institucional pode ser compreendido como um processo intencional e otimizante? E se a mudança institucional não é um processo regido pela lógica das consequências, o que explicaria esse processo? O debate sobre os mecanismos de mudança institucional tem início nos trabalhos de Hume e Adam Smith e continua ao longo dos anos seguintes percorrendo praticamente todo o século 19 e 20 . Ao longo das últimas três décadas, esse debate tem ganhado um novo impulso com o advento do neoinstitucionalismo nas suas diversas vertentes.

Dentre os aspectos que têm despertado mais atenção dos neoinstitucionalistas, desatacam-se as questões referentes ao papel dos agentes e das estruturas sociais e políticas no processo de mudança. Há consenso de que, em última instância, todas as instituições surgem e se modificam em função da atuação de indivíduos. Em outras palavras, é a intervenção individual (agência) que transforma as instituições. No entanto, a intervenção individual não é isenta, soberana e autônoma. Ela se insere em um contexto social e político específico e quase sempre se manifesta de forma complexa, mediante uma longa e complicada cadeia de interações e em decorrência de uma série de eventos nem sempre intencionais ou adequadamente previstos. Pierson (2004) lista diversos obstáculos para a percepção do processo de mudança institucional como sendo guiado por indivíduos movidos pela lógica das consequências. São eles: (i) instituições possuem múltiplos efeitos, que se manifestam de maneira assimétrica, portanto há dificuldades em prever com precisão os ganhos e perdas; (ii) inovações institucionais tendem a ser orientadas por mimetismo ou seguindo a lógica da adequação, ou seja, os inovadores, em vez de otimizar, seguem os possíveis retornos e tendem a buscar um design institucional adequado aos papéis que têm que desempenhar; (iii) o horizonte de tempo pertinente para os inovadores é normalmente menor do que o da duração das instituições que pretendem criar; (iv) os efeitos das inovações institucionais são ambíguos e incertos, ou seja, não são claramente compreendidos e muitas vezes não podem ser adequadamente previstos; ( $v$ ) os efeitos das mudanças institucionais podem se alterar na medida em que o ambiente em que elas se inserem se altera; (vi) novos atores podem surgir e reinterpretar a natureza e a aplicabilidade das 
instituições. Os estudos históricos sobre mudança institucional tendem a focalizar atenção na importância de conjunturas críticas como ponto de partida para ruptura e inovação. É ao longo desses momentos de crise que os agentes se sobressaem e conseguem se impor sobre as pressões decorrentes da estrutura. Conjunturas críticas gerariam mudanças do tipo "equilíbrio pontilhado", como preconizado por Jones e Baumgartner (1993). Modelos mais recentes que defendem a existência de processos de dependência da trajetória (path dependence) se enquadram nesse mesmo arcabouço e têm como ponto de partida a presença de conjunturas críticas guiando a mudança institucional.

Uma perspectiva alternativa foi proposta por Thelen (2003) e seus colaboradores (StreeCK; Thelen, 2005; MAhoney; Thelen, 2010). A partir de estudos realizados com base na trajetória do sistema de educação vocacional na Alemanha e em vários outros países da OCDE, Thelen sugere que há muito mais continuidade nesses pontos de aparente ruptura e muito mais mudança nesses períodos de aparente continuidade. Mais ainda, Thelen reinsere os atores nesses processos de mudança e propõe um novo olhar para a relação entre agência e estrutura nas inovações institucionais.

Em trabalho recente, Mahoney e Thelen (2010) apresentam um modelo básico para explicar diferentes formas de mudança institucional (ver Figura 1 adiante). A concepção teórica de Mahoney e Thelen (2010) afirma que ambas as características, do contexto político e da instituição em questão, conduzem a um tipo de mudança institucional esperada (relação I). Esse fato acontece porque a forma institucional e o contexto político influenciam o tipo dominante de agente de mudança (relação III) que irá surgir e se desenvolver num contexto institucional específico (relação II).

Mahoney e Thelen (2010) propõem, ainda, a partir de reflexões anteriores (STREECK; THELEN, 2005; THELEN, 2003), uma teoria da mudança institucional gradual. A contribuição dos autores parte da crítica de que a maioria dos estudiosos da área tem concentrado suas pesquisas nas consequências de choques exógenos, que trazem algumas reconfigurações institucionais básicas, e negligenciam mudanças que são baseadas em desenvolvimentos endógenos, que frequentemente se desdobram incrementalmente.

A proposta dos autores esquematiza quatro tipos formais de mudança institucional gradual. O primeiro é o deslocamento (displacement), em que acondicionamentos tradicionais são desacreditados e impelidos ao largo em favor de novas instituições e lógicas comportamentais associadas. Em segundo lugar, há o acréscimo em camadas (layering), a mudança que põe em marcha caminhos que alteram uma dada dinâmica por meio de um mecanismo denominado crescimento diferenciado. Assim, a introdução de novos elementos desencadeia uma dinâmica 
que, ao longo do tempo, pode-ativamente-expulsar ou suplantar sistemas antigos, já que o domínio dos últimos sistemas progressivamente faz com que os primeiros se retraiam. Outro tipo de mudança institucional é o deslizamento (drift), que parte da constatação de que a constância institucional nunca é automática, apesar do termo "instituição" estar relacionado com a ideia de estabilidade e aderência (STREECK; THELEN, 2005). Desse modo, segundo Thelen (2003), instituições requerem uma manutenção ativa. A fim de permanecer o que são, as instituições precisam ser repostas e reorientadas e, em alguns casos, ser reavaliadas e renegociadas, em resposta às mudanças no ambiente político e econômico no qual elas estão incorporadas (STREECK; THELEN, 2005). Se essa manutenção é deliberadamente negada, a instituição pode não sobreviver. Finalmente, a conversão (conversion) é entendida como uma forma de mudança institucional diferente dos denominados "acréscimos em camadas" e "deslizamento". Nesse tipo de mudança institucional, as instituições não são muito desfiguradas ou propensas à decadência, já que são redirecionadas para novos objetivos, funções ou escopos. Esse redirecionamento pode acontecer por meio de novos desafios ambientais, mudanças nas relações de poder e contestações políticas acerca das funções e propósitos a que uma dada instituição deveria servir.

Cada tipo é definido por meio da ponderação acerca do ponto em que a transformação institucional acontece. O entendimento desses diferentes tipos de mudança institucional, incluindo aí os papéis que defensores institucionais e seus desafiantes desempenham, prepara o terreno para a análise de como e por que um tipo pode ocorrer com mais frequência que outro. A teoria proposta destaca então os diferentes tipos de agentes de mudança, cujas estratégias diferenciadas (insurrectionaries, symbionts, subversives e opportunists) irão desenvolver-se em ambientes institucionais específicos (MAHONEY; THELEN, 2010). Mahoney e Thelen (2010) demonstram as diferenças entre esses tipos de agente de mudança, por meio de duas questões básicas: (i) o ator busca preservar as regras institucionais existentes?; e (ii) o ator cumpre as regras institucionais? Os autores concluem que existe uma extensa agenda de pesquisa potencial, por meio de novos conceitos e suposições causais propostas.

\section{O papel dos atores institucionais}

De modo a se entender o papel de atores na elaboração, transformação, manutenção e desmembramento de instituições, é necessário introduzir o conceito de institutional work (ação institucional) (LAWRENCE; SUDDABY, 2006). O trabalho desses autores permite um exercício de complementariedade com teoria da mudança institucional (MAHONEY; THELEN, 2010), assim como dos tipos de agente 
de mudança já citados. De fato, a intenção de Lawrence e Suddaby (2006) ao chamar a atenção sobre pesquisas acerca do papel de atores, é propor o conceito de institutional work (ação institucional) para descrever a ação intencional de indivíduos e organizações com o objetivo de criar, manter e desfazer instituições. Segundo os autores, apesar do aporte de outros pesquisadores, a contribuição de DiMaggio (1988) e Oliver $(1991,1992)$ é um dos componentes teóricos fundamentais que sinalizarão a mudança do interesse de pesquisadores institucionalistas para o impacto de atores individuais e coletivos sobre instituições que regulam os campos nos quais eles atuam. O outro é inspirado nos estudos da sociologia da prática, que enfoca a ação localizada de indivíduos e grupos e como eles lidam e tentam reagir às demandas do dia a dia (LAWRENCE; SUDDABY, 2006). A partir de uma extensa revisão de literatura, os referidos autores apresentam conjuntos distintos de práticas por meio das quais atores encarregam-se de ações que resultam na criação, manutenção e desmantelamento de instituições. O conceito de ação institucional destaca, assim, o esforço e as práticas engenhosas dos atores.

Examinando os modelos de mudança institucional de Lawrence e Suddaby (2006), Streeck e Thelen (2005) e Mahoney e Thelen (2010), percebem-se pontos críticos que merecem ser analisados com maior profundidade. Lawrence e Suddaby (2006) avançam em relação ao modelo proposto por Oliver (1991, 1992), incluindo novas categorias. No entanto, também não estabelecem possíveis relações causais entre as ações institucionais descritas e o contexto do qual elas poderiam surgir. Por outro lado, Streeck e Thelen (2005) e Mahoney e Thelen (2010) desenvolvem um modelo (Figura 1) em que a relação de causalidade é especificada, porém, os autores só consideram o contexto político, e não o social e funcional. Também não levam em consideração as ações estratégicas de atores (LAWRENCE; SUDDABY, 2006). De fato, a concepção teórica de Mahoney e Thelen (2010) afirma que ambas as características, do contexto político e da instituição em questão, conduzem a um tipo de mudança institucional esperada (relação I). Esse fato acontece, ainda segundo os autores, porque a forma institucional e o contexto político influenciam o tipo dominante de agente de mudança (relação III) que irá surgir e se desenvolver num contexto institucional específico (relação II).

A proposta de investigação que então se apresenta é pesquisar o comportamento dos principais atores responsáveis por processos de mudança (no caso, criação de ouvidorias de agências federais) frente às possíveis ações de criação, desenvolvimento e desmantelamento de instituições. Para tanto, como sintetizado na Figura 1, sugerese a inserção (na cor cinza), no modelo original proposto por Mahoney e Thelen (2010), das contribuições conceituais de Lawrence e Suddaby (2006). A Figura 1 expõe essa sugestão de estrutura teórica. Propõem-se essas inserções em consequência das limitações que o modelo de Mahoney e Thelen (2010) apresenta. 
Observa-se na Figura 1 uma seta bidirecional. Essa seta, que relaciona o tipo dominante de agente de mudança (MAHONEY; THELEN, 2010) e as formas de ação institucional desses agentes (LAWRENCE; SUDABBY, 2006), explica-se pela possibilidade de detalhar que ações institucionais os tipos de agentes descritos por Mahoney e Thelen (2010, p. 23) podem exercer. Em outras palavras, auxilia a entender mais especificamente quem está fazendo o quê.

\section{Figura 1 - Modelo analítico proposto}

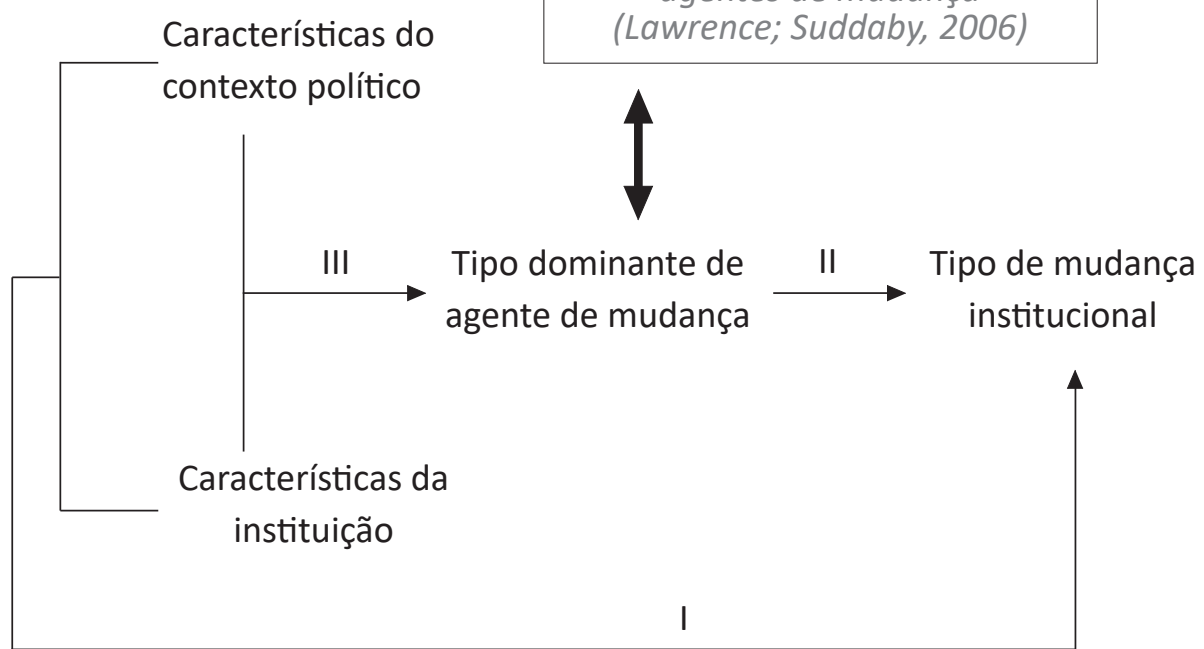

Fonte: Elaboração própria, com base em Mahoney e Thelen (2010) e Lawrence e Suddaby (2006).

O objetivo do esforço de concepção de um modelo analítico aperfeiçoado, agregando a contribuição de Lawrence e Suddaby (2006) ao modelo de Mahoney e Thelen (2010), foi a aproximação mais fidedigna de como a realidade se apresenta nessa dinâmica e, dessa forma, poder responder à pergunta de pesquisa.

\section{Design e composição da pesquisa}

Estudos sobre ouvidorias públicas no Brasil ainda são muito incipientes. Existem alguns estudos sobre ouvidorias de segurança ou de saúde, e a maioria das análises preocupa-se em utilizar um enfoque qualitativo, por meio de estudos de caso e técnicas de coleta como entrevistas e pesquisa bibliográfica e documental. O enfoque quantitativo é percebido em poucos trabalhos, e incluído como suporte para a análise dos dados. Os resultados se baseiam em sua maioria em análise de conteúdo e documental. Assim, temos um número razoável de pesquisas que têm utilizado a 
configuração do estudo de caso para entender o surgimento das ouvidorias, e essa foi a opção nesta investigação. Os procedimentos seguidos para estruturação da pesquisa foram os seguintes: análise exploratória inicial; seleção dos casos; construção do código de análise; seleção dos documentos, legislação e dos entrevistados; coleta dos documentos e legislação, e aplicação das entrevistas; análise dos documentos, legislação e entrevistas; elaboração dos relatórios de análise.

Após a escolha do espaço de investigação - ouvidorias das agências reguladoras federais -, foi feito um levantamento das informações básicas das dez agências, por meio de seus respectivos sítios eletrônicos e legislação pertinente. É interessante observar que somente três agências - Antaq, ANTT e Anac -, das quatro mais recentemente criadas, incluem nas suas respectivas leis de criação competências específicas para o ouvidor, destacando assim sua função frente à equipe da ouvidoria. A Lei no 10.233/2001, que criou a Antaq e a ANTT, versa, no seu art. 63, que:

Art. 63. O Ouvidor será nomeado pelo Presidente da República, para mandato de três anos, admitida uma recondução.

Parágrafo único. São atribuições do Ouvidor:

I - receber pedidos de informações, esclarecimentos e reclamações afetos à respectiva Agência, e responder diretamente aos interessados;

II - produzir semestralmente, ou quando a Diretoria da Agência julgar oportuno, relatório circunstanciado de suas atividades.

Já a Lei no 11.182/2005, que versa sobre a criação da Anac, lista, no seu art. 18, as competências do indivíduo que ocupará o cargo de ouvidor de uma forma muito parecida com a ANTT e Antaq, com apenas algumas diferenças sutis:

Art. 18. O Ouvidor será nomeado pelo Presidente da República, para mandato de 2 (dois) anos.

Parágrafo 10 Cabe ao Ouvidor receber pedidos de informações, esclarecimentos, reclamações e sugestões, respondendo diretamente aos interessados e encaminhando, quando julgar necessário, seus pleitos à Diretoria da ANAC.

Parágrafo 2 O O Ouvidor deverá produzir, semestralmente ou quando a Diretoria da ANAC julgar oportuno, relatório circunstanciado de suas atividades.

Das dez agências reguladoras federais existentes, esta pesquisa destaca a ANTT e Antaq, denominadas agências irmãs, como objeto de investigação. Por que "agências irmãs"? Como citado anteriormente, ambas as agências foram criadas pela mesma lei e, consequentemente, receberam a mesma orientação legal acerca do papel da ouvidoria e, especificamente, do ouvidor. A questão que então se apresenta é: já que são agências com a mesma constituição normativa, os processos e mecanismos de mudança institucional estão seguindo o mesmo padrão? 
Para dar continuidade à pesquisa, foi solicitado, por meio de carta a cada ouvidor, acesso para entrevistas, além de permissão para observação não participante. Ambas as ouvidorias aceitaram as entrevistas, mas, curiosamente, ambas negaram acesso para observação. $O$ argumento conjunto foi que as ouvidorias lidam com certo tipo de informação (diferentes tipos de denúncias) que, na maioria das vezes, é sigilosa, e, por isso, a presença dos pesquisadores poderia inibir tanto o denunciante quanto o trabalho dos funcionários.

O processo da coleta de dados foi estruturado em duas fases: (1) pesquisa documental; e (2) entrevistas semiestruturadas. A pesquisa documental foi elaborada a partir do levantamento e leitura prévia dos relatórios institucionais das cinco agências pesquisadas. Além disso, leis, portarias, medidas provisórias, decretos e pareceres relacionados às ouvidorias em questão também foram localizados e lidos. Durante essa pesquisa, foi feito um levantamento, em cinco jornais de grande circulação nacional, de informações sobre as agências pesquisadas. Já a escolha dos entrevistados seguiu os condicionantes de: ocupante e ex-ocupante do cargo de ouvidor; ou servidores de carreira, ou ocupantes de cargos em comissão, há mais tempo na respectiva ouvidoria. Foram entrevistados três informantes, entre os meses de março e abril de 2013, num total de 185 minutos de gravação.

A análise dos dados foi iniciada com a construção do código de análise. Em seguida, o processo de análise documental procurou caracterizar a forma de registro dos dados. Após organizados, os dados foram examinados para tentar detectar temas mais frequentes (LÜDKE; ANDRÉ, 1986). Após essa rodada de classificação para as duas ouvidorias, foram construídas tabelas, para cada uma, onde são destacados das falas coletadas extratos dessas que exemplificam cada código de análise. O objetivo nessa etapa foi contrapor, por meio dos códigos de análise, o que foi percebido, das falas dos entrevistados, acerca de cada elemento do modelo teórico, para cada agência, separadamente. Quadros-resumo foram elaborados, onde se verificava as linhas do tempo dos acontecimentos e relatórios de atividades das agências e de suas ouvidorias. Em seguida, foi elaborada uma descrição histórica para cada agência e sua ouvidoria.

Em contraponto à visão tradicional das instituições moldando os comportamentos dos atores, os limites da influência desses atores nos movimentos de institucionalização de ouvidorias não são claros. Dessa forma, na fase final da análise, as evidências foram cotejadas com o modelo teórico de mudança institucional de Mahoney e Thelen (2010), conjugado com as contribuições de Lawrence e Suddaby (2006). Buscando apreender enfoques sobre a realidade das ouvidorias das agências, as seções a seguir apresentam e discutem os resultados e implicações das pesquisas exploratória, documental e entrevistas. 


\section{A Ouvidoria da Agência Nacional de Transportes Aquaviários (Antaq)}

A Antaq foi criada em 2001, com a reestruturação do Ministério dos Transportes, quando também foi criado o Conselho Nacional de Integração de Políticas de Transporte (Conit), a Agência Nacional de Transportes Terrestres (ANTT), e o Departamento Nacional de Infraestrutura de Transportes (DNIT), e extintos o Departamento Nacional de Estradas de Rodagem (DNER) e o Grupo Executivo de Integração da Política de Transportes (Geipot). Foi instalada em 17 de fevereiro de 2002, como uma autarquia federal vinculada ao Ministério dos Transportes, respondendo pela implantação das políticas públicas executadas por aquela pasta, nos termos da sua lei de criação, bem como pelo estabelecimento das políticas e diretrizes a cargo da Secretaria de Portos da Presidência da República. A Ouvidoria da Antaq parece atuar com independência, não havendo vinculação hierárquica regulamentar com a Diretoria Colegiada, o Conselho Consultivo, a Corregedoria ou com a Procuradoria. No entanto, se observado o organograma da agência, vê-se que a Ouvidoria não está em posição de staff, e sim abaixo da Diretoria.

\section{Principais aspectos da trajetória de institucionalização da Ouvidoria da Antaq}

A análise do histórico da Antaq e de sua ouvidoria aponta para a mudança institucional do tipo conversão (MAHONEY; THELEN, 2010), em que se percebe que a existência de imprecisões nas normas provoca o acesso de agentes de mudança - os oportunistas - que têm como objetivo buscar adequação de procedimentos, normas e regras, explorando a já citada ambiguidade dessas para impor sua própria agenda.

A Ouvidoria da Antaq teve o seu primeiro ouvidor nomeado em março de 2002, com mandato concluído em fevereiro de 2005. Nessa época, tanto a agência como a ouvidoria estavam ainda se estruturando, e já enfrentavam problemas práticos de infraestrutura precária e falta de pessoal - como citado anteriormente, o relatório de 2003 da agência aponta que o único funcionário da área é o próprio ouvidor. Nesse período, é transferida do Ministério dos Transportes uma servidora, que permaneceu desde essa data até hoje (agosto 2015) na ouvidoria. Assim, com apenas o titular e uma assessora, a Ouvidoria da Antaq inicia seus trabalhos.

Outra questão interessante foi a opção da diretoria colegiada, desde esse período, de divulgar um relatório único, tanto da agência como da sua ouvidoria. $A$ despeito disso, não foi observado, como comentado anteriormente, apontamentos da ouvidoria nos relatórios de 2004 a 2009. Nesse meio tempo, a titularidade do setor passa para Paulo R. Vieira, que cumpre o seu primeiro mandato entre 
novembro de 2005 a novembro de 2008; é reconduzido, mas interrompe o mandato, a pedido, em maio de 2010. Dois meses depois, é nomeado Jailson Santos Soares, mas esse é afastado de suas funções pela Presidência da República em 27 de novembro de 2012. Alguns dias depois, assume, como ouvidora interina, a funcionária transferida do Ministério dos Transportes, citada no parágrafo anterior. É interessante refletir, então, quais as possíveis consequências dessa precariedade para a institucionalização da ouvidoria, tanto na exposição das suas atividades quanto na titularidade do setor.

Não fica claro, ao analisar os relatórios da agência entre 2004 e 2009, o porquê de não divulgar as atividades da ouvidoria. Sabe-se, no entanto, por meio da entrevista feita com a ouvidora interina, que, ainda na gestão do primeiro ouvidor, foi instalado um call center - dentro da própria ouvidoria - para processar as demandas dos usuários. Com apenas duas atendentes terceirizadas, a ouvidoria da Antaq é o único caso estudado em que o call center se localiza dentro do espaço da própria ouvidoria. Ainda, antes do término do mandato do primeiro ouvidor, uma visita do Tribunal de Contas da União apontou que se fazia necessário que a ouvidoria registrasse, através de protocolo, a demanda e acompanhasse cada processo até a sua finalização, o que não era feito até então. Nessa época, aconteceu a implantação do primeiro sistema informatizado para processamento dessas demandas.

Já na gestão do segundo ouvidor foi implantado o segundo e atual sistema informatizado, para que suportasse de forma mais rápida e transparente as demandas, os registros de protocolos e os documentos produzidos pela agência para consulta da população, todos eles com acesso via sítio eletrônico. Na questão da transparência, especificamente, o objetivo era dinamizar o tempo de resposta à demanda e favorecer a satisfação do usuário. O sistema antigo não tinha como mensurar esses dois índices. Esse novo sistema entrou em funcionamento em 2009. Na gestão do terceiro ouvidor, esse sistema é aprimorado uma vez mais, para responder às exigências do Tribunal de Contas da União (TCU) e da Ouvidoria Geral da União (OGU). Nos últimos três anos, após o desenvolvimento de um fluxograma de trabalho para modelar o atendimento, principalmente no tocante às reclamações e denúncias, definiu-se que, conforme urgência e necessidade de cada caso, é instaurado um procedimento de fiscalização em cumprimento ao Plano Anual de Fiscalização (PAF), plano esse definido e atualizado anualmente.

Ressalta-se então que a Ouvidoria da Antaq tem um histórico de fragilidade estrutural e que ainda está construindo sua autoridade, tanto para a agência quanto para a própria sociedade. À época da entrevista, em março de 2013, a ouvidora interina afirmou que estava em tramitação um acórdão para retirar o call center de dentro do setor e colocá-lo em outro espaço, o que já acontece nas outras ouvidorias estudadas. Esse acórdão, feito junto ao TCU, prevê também aprimorar a estrutura física e de pessoal da ouvidoria. Assim, observa-se que a apresentação da descrição 
histórica da Ouvidoria da Antaq aponta, em relação ao tipo de ação institucional, para a criação (LAWRENCE; SUDDABY, 2006) de instituições. Como dito acima, o setor inicia seus trabalhos com poucas informações, sendo que essas apresentam várias lacunas para o desenvolvimento de rotinas de trabalho. Ao longo do tempo, a ouvidoria, sem questionar as regras impostas quando da criação da própria agência, as aperfeiçoa, detalha e aprimora, buscando cumprir seus objetivos, ainda que pouco explanados legitimamente.

\section{A Ouvidoria da Agência Nacional de Transportes Terrestres (ANTT)}

A agência, criada em 2001, tem definido como missão institucional "assegurar aos usuários adequada prestação de serviços de transporte terrestre e exploração de infraestrutura rodoviária e ferroviária outorgada" (AGÊNCIA NACIONAL DE TRANSPORTES TERRESTRES, 2012p. 05). No organograma da ANTT, a ouvidoria se encontra numa posição de subordinação hierárquica em relação ao Diretor-Geral da agência.

\section{Principais aspectos da trajetória de institucionalização da Ouvidoria da ANTT}

Assim como a Antaq, a análise do histórico da ANTT e de sua ouvidoria aponta para a mudança institucional do tipo conversão (MAHONEY; THELEN, 2010), em que se apreende que ambiguidades nas normas provocam o acesso de um agente de mudança - os oportunistas - que têm como objetivo buscar adequação de procedimentos, normas e regras, explorando a já citada ambiguidade dessas para impor sua própria agenda.

O histórico da Ouvidoria da ANTT aponta para algumas questões de relevância: na sua criação, o setor ficou sob a responsabilidade do corregedor de julho a novembro de 2002, quando o primeiro ouvidor assume o cargo, e o cumpre até o final, em novembro de 2005. O texto aponta a falta de estrutura física, de pessoal e de informações para a implantação da ouvidoria, nessa época. Essa falta de estrutura se refletia, inclusive, em como o atendimento ao usuário era feito: até dezembro de 2002, esse era feito por meio de uma central telefônica do próprio Ministério dos Transportes. Outra questão importante foi o início de funcionamento, em janeiro de 2003, da Central de Atendimento 0800 da própria ANTT, mas através de terceirizados, o que reflete o início da construção de autonomia para o funcionamento da ouvidoria. No entanto, esse atendimento era precário, já que a equipe contava com 25 pessoas, sendo 15 delas exclusivamente para atendimento telefônico, e apenas em horário comercial (das $8 \mathrm{~h}$ às $18 \mathrm{~h}$ horas, de segunda a sexta-feira). 
Com o passar do tempo, aumentaram expressivamente os contatos telefônicos junto à ANTT, como, por exemplo, acerca da Lei do Passe Livre, cuja responsabilidade é do Ministério dos Transportes, e não da agência. Essa situação aconteceu após a desativação da central de atendimento daquele ministério. Isso confirma o depoimento de um dos entrevistados da Ouvidoria da ANTT, que comenta que a maioria (92\%) dos contatos feitos pelos usuários é de pedido de informação, e não reclamação ou denúncia, ao contrário do acontece nas outras ouvidorias pesquisadas. Com a divulgação da Resolução no 79, ainda em 2002, a ouvidoria faz o primeiro grande esforço para se fazer conhecida pelos usuários, já que essa resolução aponta como direito do consumidor "levar ao conhecimento do órgão de fiscalização as irregularidades de que tenha conhecimento, referentes ao serviço delegado".

Em dezembro de 2005, assume o segundo Ouvidor da ANTT, que cumpre seu mandato até 2011, ou seja, nesse caso, houve a recondução do ouvidor. Em fevereiro de 2009, acontece outro aspecto relevante para institucionalização da ouvidoria - a implantação de um call center, terceirizado, fora da estrutura da própria ANTT. Esse call center conseguiu se desenvolver para atender a $100 \%$ das chamadas, cumprindo assim exigência do TCU, de gravar todas as chamadas, registrá-las e, a partir disso, fornecer à ouvidoria dados importantes para contribuir com a gestão da agência. $O$ atual Ouvidor da ANTT assumiu em fevereiro de 2012, e foi reconduzido ao cargo em fevereiro de 2015. O ouvidor promove, ao longo de 2012, a implantação do tridígito (166) para contato do usuário com a agência. O tridígito tem como objetivo facilitar o acesso de parcela da população brasileira particular: pessoas com deficiência que utilizam o passe livre, idosos e outros com dificuldade de utilizar a informática como mecanismo de contato com a ouvidoria.

Ultimamente, a ouvidoria está reformulando o processo de atendimento, pensando em como irá orientar o usuário, quando a demanda desse for uma reclamação de fato pretérito, para que esse registre primeiro sua questão na própria empresa regulada. Como isso ainda não está sendo feito, a ouvidoria da ANTT ainda debate com as suas reguladas sobre as reais exigências que a agência está fazendo a cada uma. Um importante fato decorrente desse dilema é o início do desenvolvimento de parceria da ouvidoria com a Superintendência de Fiscalização da ANTT, para criar um projeto de fiscalização das reguladas em tempo real. Dessa forma, observa-se que a apresentação da descrição histórica da ouvidoria da ANTT demonstra, acerca do tipo de ação institucional, criação (LAWRENCE; SUDDABY, 2006) de instituições. Como já mencionado, em concordância com as ouvidorias antes discutidas, o setor principia suas tarefas com poucas informações, sendo que essas apresentam várias lacunas para o desenvolvimento de rotinas de trabalho. Ao longo do tempo, a ouvidoria, sem questionar as regras impostas quando da criação da própria agência, as aperfeiçoa, detalha e aprimora, buscando cumprir seus objetivos, ainda que pouco elucidados validamente. 


\section{Análise das evidências: mudança institucional}

Esta subseção irá debater como as características de contexto político e das instituições estão influenciando o tipo específico de mudança institucional que surge na análise das evidências, ou seja, como apresentado na Figura 1, a relação que Mahoney e Thelen (2010) denominam I. Com base nos estudos sobre mudança institucional, nós esperaríamos que a combinação de contexto político e de características da instituição nos indicasse um tipo específico de mudança institucional, a saber, o denominado deslizamento, em que se nota a manutenção das regras existentes, apesar do ambiente externo sugerir mudanças. Para tanto, precisaríamos observar características do contexto político com fortes possibilidades de veto, ou seja, notar o acesso de atores aos meios institucionais (ou extrainstitucionais) para inibir mudanças, além de certas características das instituições, implicando que essas dariam pouco espaço para escolha, tanto na interpretação quanto no cumprimento de suas regras. A análise focalizou, dessa maneira, a legislação específica de criação das agências reguladoras pesquisadas, com ênfase quanto a seus regimentos internos. O resultado sugere que a mudança institucional do tipo deslizamento, de fato, deveria acontecer, se a pesquisa focalizasse somente a análise dos documentos oficiais, como as leis de criação das agências e seus respectivos regimentos internos. Por exemplo, a Lei no 10.233/2001, que criou a ANTT e a Antaq, descreve que:

[...] Art. 52. A ANTT e a ANTAQ terão Diretorias atuando em regime de colegiado como órgãos máximos de suas estruturas organizacionais, as quais contarão também com um Procurador-Geral, um Ouvidor e um Corregedor. [...] (grifo nosso).

$O$ atual regimento interno da ANTT diz que a sua ouvidoria é vinculada à diretoriageral. A mesma situação é observada na Antaq: o art. 5o da última alteração do regimento interno, aprovado em 2012, afirma que a ouvidoria faz parte da diretoria geral. Porém, ressalta-se que, no regimento interno original, de 2006, é citado que "Art. 70 A Ouvidoria, no exercício de suas atribuições, atuará com independência". Adiante, o regimento descreve as competências do setor, e aponta uma vinculação sutil com a diretoria:

Art. 26. À Ouvidoria compete: I - receber reclamações, pedidos de informações e de esclarecimentos afetos à esfera de atuação da Antaq, e responder diretamente aos interessados; II - produzir semestralmente, ou quando a Diretoria julgar oportuno, circunstanciado relatório de suas atividades (grifo nosso). 
Dada essa combinação, poderíamos esperar, então, a prevalência de um tipo específico de mudança institucional: o deslizamento, mediante a atuação de agentes que exploram instituições com o objetivo de ganho próprio, apesar de confundir a eficácia da instituição com suas ações. De fato, esses agentes exploram o caráter da regra, enquanto transgridem seu fundamento. Esses agentes são denominados agentes simbiontes parasitários. O resultado da análise das entrevistas e dos relatórios semestrais e anuais das ouvidorias aponta para a existência, entretanto, de um contexto político com características de fraca possibilidade de veto. Já as características das instituições apresentaram-se, na maioria das vezes, com um alto poder discricionário na interpretação e na implementação das ações das ouvidorias, conforme evidências a seguir.

Da criação da ANTT, em junho de 2001, até a posse do primeiro ouvidor, em novembro de 2002, o corregedor ocupou-se também das responsabilidades da ouvidoria: "[...] em 2001 era o corregedor que fazia papel de ouvidor, também foi no começo, instalação da agência, né, tava criando estrutura" (Depoimento de um dos entrevistados - ANTT). A agência contava com uma infraestrutura muito pequena no início, a então equipe da ouvidoria (terceirizada) é que fazia os atendimentos telefônicos; como consequência, à época, 50\% da demanda ficavam sem resposta, por falta de equipe. Cabe registrar que, no ato de criação da ANTT, não consta um item que diferencie um setor de atendimento do setor da ouvidoria. Sobre essa ouvidoria:

\footnotetext{
A Ouvidoria está sempre em um processo de transformação e crescimento, né. Com o início da agência, quer dizer, ela começou bem pequena, com uma infraestrutura bem limitada [...]. No começo mesmo da agência, quem fazia os atendimentos telefônicos eram as pessoas que trabalhavam na Ouvidoria, terceirizados, mas assim não tinha a contratação de um "call center". $E$ quando cheguei na Ouvidoria em 2006, a gente estava nessa situação. A gente tinha já um 0800 funcionando e tinha uma equipe de terceirizados, que fazia o atendimento dentro da Ouvidoria, a gente tinha tipo um mini "call center" dentro da Ouvidoria (Depoimento de um dos entrevistados - ANTT).
}

Hoje em dia, a ANTT tem um call center terceirizado que concentra a demanda que os profissionais da ouvidoria denominam de "primeiro nível". Se o usuário não ficar satisfeito e acionar o setor, aí sim a Ouvidoria inicia os procedimentos chamados de "segundo nível". Observa-se, nas falas dos entrevistados da ANTT, o mesmo comentário feito nas agências anteriores acerca do ocupante do cargo de ouvidor: que suas ações dependem da sua personalidade, ou seja, de quem está ocupando o cargo no momento. Comprova-se isso, por exemplo, quando se comenta sobre as relações da ouvidoria com outros setores da agência. A fala do entrevistado ressalta 
que o atual ouvidor tem um bom relacionamento, pois já ocupava o cargo de chefe de gabinete num período anterior: "[...] então ele [o atual ouvidor] já tem um bom relacionamento na agência toda, conhece toda a estrutura, já conhece todo mundo e isso facilita, né [...] então é tranquilo, não temos tido problema não" (Depoimento de um dos entrevistados - ANTT).

Na Ouvidoria da ANTT, "hoje a maioria da nossa equipe é terceirizada" (Fala de um dos entrevistados - ANTT). O setor ainda está construindo uma identidade dentro da agência, e luta para entrar em sintonia com as áreas mais demandadas, como, por exemplo, a de fiscalização. No organograma da agência, a ouvidoria encontra-se subordinada ao conselho diretor. Mas isso não impediu os constantes posicionamentos que o atual ouvidor teve de assumir, tendo em vista enfrentar os problemas de transparência e accountability da agência. Vale ressaltar que, à época das entrevistas, todos os diretores da agência eram interinos. Sobre essa situação e seus reflexos:

E a outra coisa que eu tô querendo começar a fazer, já mantive contatos o ano passado, mas até em função dessa transitoriedade, toda a gente fica assim esperando, porque uma definição pra ver, porque de repente tô com uma ideia, vendo uma política pra se fazer um tipo de ação na Ouvidoria que um diretor pode concordar, mas infelizmente ele ainda pode estar numa situação de interino, muda-se no dia seguinte, na semana seguinte, mês seguinte, o outro fala - não, mas eu não concordo com isso, acho que tem que ser de outra forma, a gente começa a ter que refazer, mexer no trabalho [...] (Depoimento de um dos entrevistados - ANTT).

A análise da ouvidoria da Antaq demonstrou que, entre as duas estudadas, essa foi a que mais padeceu em consequência de constantes mudanças estruturais. Desde a sua fundação, em 2001, a agência sofreu um total de doze modificações no seu regimento interno. Essas modificações traduzem uma busca de aprimoramento na estrutura organizacional da Antaq, assim como uma melhor definição das competências de seus setores e unidades regionais. Mas, por outro lado, elas trouxeram insegurança para que a sua ouvidoria se institucionalizasse frente aos demais setores.

Assim, a Antaq inicia seus trabalhos de forma precária: "[...] quando eu cheguei, a Antaq estava vazia no seu todo, ou seja, em 2002 [...] (Depoimento da atual [agosto 2015] ouvidora interna - Antaq)". Observa-se, inclusive, um esvaziamento da equipe da ouvidoria, principalmente após o afastamento do último ouvidor nomeado. Quem ocupa o cargo hoje é a ouvidora interina. Inclusive, ela é a única do setor, atualmente, que não é terceirizada. "[...] a equipe tá reduzida, só tem terceirizado, só tem eu [a atual ouvidora interina] de servidora no momento [...]" 
(Depoimento da atual [agosto 2015] Ouvidora Interina-Antaq). Não há comentários sobre a independência financeira do setor, e a equipe é menor do que a da ANTT. É, também, a única ouvidoria das agências reguladoras federais cujo call center está inserido nela, impondo uma sobrecarga de trabalho. Quando perguntado se a respondente acreditava que a ouvidoria estava institucionalizada, a atual ouvidora interina responde que:

Não... sim, sim, com essas ressalvas, com essas observações a fazer, pontuações que o TCU recomendou fazer, que é a questão, tá tramitando um acórdão, um processo que recomenda a instalação do call center, inclusive eu me pronunciei ontem, anteontem, a respeito desse acórdão, foi, o que eu recomendaria, qual seria minha sugestão, então assim, desde que a Ouvidoria foi institucionalizada, que o call center é aqui dentro [...] foi evoluindo os anos, foi passando os anos, mas a inserção do 0800 continua a mesma, os dirigentes acharam que isso não necessitaria da instalação isolada, ou seja, fora da ouvidoria, dentro só do âmbito da Antaq, fora da ouvidoria, a instalação do call center. Houve um certo acordo entre os dirigentes que isso não seria necessário (Depoimento da atual Ouvidora Interina - Antaq).

Durante uma das reestruturações, a assessoria de comunicação, que gerenciava o Fale Conosco da agência, também foi redirecionada para o setor. Por estar interina no cargo (desde novembro/2012), a atual (agosto 2015) ouvidora apresenta um poder propositivo praticamente inexistente. Na sua fala, é possível perceber o desconforto em sugerir algo:

Ele [o ouvidor] pode modificar e dar a resposta, todos sabem disso, com a assinatura dele embaixo. Só que o recomendado é que não modifique muito, por quê? Porque vem de um setor que, o setor está apto a responder e convive com a situação. Se um processo $X$, lá... cinco volumes como veio para mim outro dia. Eu vou ler todos os volumes? Não, eu vou ler o que diretoria $\mathrm{X}$ escreveu [...] E aí, no final, veio para cá para eu dar a resposta final, eu concordei com o relatório, despachei para o setor $X$ para tomar as providências cabíveis e tal, entendeu? (Depoimento da atual [agosto 2015] Ouvidora Interina - Antaq).

[...] às vezes eu [atual Ouvidora interina] me reporto às áreas, eu vou ao superintendente para pedir uma interpretação melhor, a gente tem que se reportar a um fórum maior, superior, lógico [...] (Depoimento da atual [agosto 2015] Ouvidora Interina - Antaq).

Esse posicionamento reflete a conduta da ouvidora e a atual dinâmica da ouvidoria. Destaca-se, finalmente, que, no organograma da Antaq, a ouvidoria está subordinada ao conselho diretor, a despeito de ser definido no art. 7o da 
Resolução no 369 que "A Ouvidoria, no exercício de suas atribuições, atuará com independência".

No modelo teórico proposto por Mahoney e Thelen (2010), o próximo elemento a ser considerado é o tipo de mudança institucional. Os atores entrevistados da ANTT apresentaram evidências de conversão, em que se destaca um exemplo de unidade de registro de regras existentes reorientadas pelos atores:

[...] desde que eu cheguei, o primeiro documento que eu peguei pra assinar eu encasquetei e ele [membro da equipe da ouvidoria] sabe. $O$ quê? A gente estava mandando a terceira ou quarta resposta para o mesmo usuário, contra a mesma empresa, resposta idêntica, dizendo que "Sua reclamação vai ser considerada, vai ser analisada, vai ser incluída numa tabela estatística, para que, em determinado momento, de acordo com o número de reclamação da empresa, seja determinada uma fiscalização na empresa" - mas já era a quarta reclamação da pessoa, mesmo assunto, não sei se o mesmo ônibus, isso aqui eu não mando, eu prefiro nem responder essa pessoa, mas isso aqui eu não mando, isso é duvidar da inteligência das pessoas, com isso aí, se a gente não acabar com a questão da tabela estatística, a gente consegue reduzir sei lá quantos por cento, passa a ser mínimo, essa coisa de não dar ao usuário a devida e, por exemplo, a resposta que ele efetivamente quer, tem usuário que acha que se você só responder, ele vai falar, as pessoas me deram atenção, mas se for aquele usuário que for um cara mais crítico, tiver um pouco mais de consciência e tudo, ele não fica satisfeito com a resposta que recebe, se a resposta já não tiver dando uma ação [...] (Depoimento do atual (agosto 2015) Ouvidor - ANTT).

No caso da Antaq, só foram localizadas evidências do primeiro tipo de unidade de registro, regras existentes reorientadas pelos atores:

E aí instaurou, averiguou, apurou, viu que realmente estava realmente irregular, pode até mudar a resolução, por exemplo, a 902 - uma dessas resoluções - está sendo alterada, está já em audiência para já modificar os pontos que estão assim em desacordo com a realidade né, eu até tento fazer minhas contribuições, é um pouco complicado, mas eu vou entrar também, estava até conversando com o gerente ontem e ele falou que são muitas contribuições. Ela vai ser alterada sim, em quase toda a sua totalidade, não é nem a questão $d a$, da, às vezes uma pequena vírgula, ou um "i", um "o", um artigo, muda o sentido da frase, e não é nem só isso, a questão da consistência das informações, né ação [...] (Depoimento do atual [agosto 2015] Ouvidor - ANTT). 
Dessa forma, as evidências empíricas a partir das falas dos atores entrevistados e da análise documental apontam para certa concentração de tipos de mudança e tipos de atores. Ao contrário do que se acreditava, as mudanças por conversão, por meio da atuação de agentes oportunistas, acontecem com mais frequência do que seria esperado. O resultado das análises (especialmente das entrevistas) aponta para a existência de contexto político com características de fraca possibilidade de veto; já as características das instituições apresentaram-se, na maioria das vezes, com um alto poder discricionário na interpretação e na implementação das ações das ouvidorias. Além disso, observa-se que não há manifestações da tipologia deslizamento ou acréscimo em camadas.

Por que isso acontece? Uma das possibilidades seria a de que, apesar de as condições do contexto político apontarem para fortes possibilidades de veto, empreendedores políticos conseguem reduzir a influência dessas possibilidades de veto, num movimento de forte para fraco. Essas evidências apontam que, talvez, o modelo de Streeck e Thelen (2010) careça da inclusão de mais uma variável - o ator institucional (LAWRENCE; SUDDABY, 2006). Como discutido na apresentação do modelo teórico, o ator institucional tem um comportamento proativo, por meio das ações de criação, manutenção ou desmembramento de instituições, ao contrário do conceito de agente de mudança descrito por Streeck e Thelen (2010), que depende de características de contextos políticos e de instituições para aflorar.

\section{Análise das evidências: tipo dominante de agente de mudança}

No modelo teórico proposto por Mahoney e Thelen (2010), outro elemento a ser considerado é o 'tipo dominante de agente de mudança'. Como discutido acima, a expectativa ao início da pesquisa era a prevalência do tipo de mudança institucional denominado deslizamento, mediante a atuação de agentes simbiontes parasitários. No entanto, o resultado da análise das entrevistas e dos relatórios semestrais e anuais das ouvidorias aponta para a frequente presença de outro tipo de agente de mudança.

A conduta relatada pelos entrevistados da ANTT confirma a tendência na percepção de agentes oportunistas. Neste exemplo, o atual ouvidor da agência explicita a atitude, defendida por ele, frente à diretoria, de não seguir o exemplo de outras agências reguladoras acerca do procedimento que o usuário deve cumprir para registrar uma ocorrência ou reclamação de um ente regulado na ouvidoria. Ele afirma: 
Aí a gente não vai obrigar, a gente vai sugerir, se ele quiser registrar direto na ANTT, hoje a gente não tem nenhuma resolução, nenhum mecanismo que determine que ele vá primeiro à empresa, então ele vai poder. No futuro pode ser que a gente faça como a Anac fez, como a Anatel fez, que a gente solicite que ele vá primeiro à empresa, porque o grande objetivo é que o problema seja solucionado e não que a gente aplique a penalidade à empresa ou uma sanção à empresa (Depoimento do atual [agosto de 2015] Ouvidor - ANTT).

Esse posicionamento é baseado na imprecisão que marca o regimento interno da agência, especificamente no que tange às funções da ouvidoria.

A análise da entrevista feita na Antaq traz evidências de que ações dos agentes de mudança podem ser consideradas de características oportunistas:

Por que na verdade a gente implantou, veja, como a gente implantou o novo sistema, o quê que aconteceu: em 2009 a gente começou, aí em 2010 o [...] [ex-Ouvidor] saiu, entrou o novo Ouvidor, aí ele recomeçou a estudar e a fazer as alterações e aí retirou os relatórios, por que não tinha tempo de resposta, e nem satisfação do usuário, então a gente resolveu não divulgar. E aí, com as alterações e recomendações internas e através dos encontros que ele teve com os outros ouvidores [...] promovidos pela OGU, e até pela ABO também, - uma instituição paralela. Para ver qual o modelo seria o mais adequado (Depoimento da atual [agosto de 2015] Ouvidora Interina - Antaq, grifo nosso).

É interessante notar que, a despeito de o regimento interno da agência definir que a ouvidoria deve produzir relatórios semestrais, esses foram suspensos por decisão unilateral do então ouvidor. Dessa forma, a expectativa da pesquisa era encontrar agentes simbiontes parasitários; no entanto, o resultado da análise apontou para o tipo de agente oportunista - observaram-se preferências ambíguas sobre a continuidade de instituições, regras ou normas. Ou seja, não há manifestações da tipologia simbiontes parasitários, insurgentes ou subversivos.

\section{Análise das evidências: formas de ação institucional}

Esta subseção ilustra a contribuição de Lawrence e Suddaby (2006) para o melhor entendimento da conduta dos atores pesquisados nesta tese. Observam-se, então, nas análises das falas dos entrevistados, evidências de ações institucionais de criação de instituições, e, particularmente no caso da ANTT, evidências também de desmantelamento dessas.

Não foi notada evidência relevante, nas entrevistas, de conduta vinculada à manutenção de instituições. A ação institucional que Lawrence e Suddaby (2006) 
definem como criação reflete três grandes grupos de atividades: (1) ação política notória, em que estão reunidas as formas de ação denominadas advocacia, determinação e aquisição; (2) ações de ênfase na reconfiguração do sistema de crenças dos atores, em que se têm as formas de ação definidas como construção de identidades, mudança de associações normativas e construção de redes normativas; e, finalmente, (3) ações concebidas para alterar classificações abstratas nas quais os limites dos sistemas de significado são alterados, cujas formas determinadas pelos autores são mimetismo, teorização e aperfeiçoamento. Já a ação institucional que Lawrence e Suddaby (2006) definem como desmantelamento reflete três formas de ação: desconexão de sanções; dissociação de fundamentos morais; e enfraquecimento de pressupostos e crenças.

A apreciação do resultado das entrevistas na ANTT apresentou evidências também de ação institucional do tipo criação, por meio da unidade de registro denominada estabelecimento de regras, através da forma de ação determinação:

Cada ouvidor que entra ele vem com algumas ideias, né, para implementar, né, ouvir algumas opiniões, ele passa um tempo pra poder entender o funcionamento tal, saber como é que tá funcionando e depois ele começa a colocar as opiniões dele e a gente começa a implementar, então o [...] [exouvidor] foi, "Ah eu acho interessante o tridígito pra poder facilitar". Então quer dizer, foi ideia dele (Depoimento de um dos entrevistados - ANTT, grifo nosso).

Além disso, a ANTT destaca-se ao apresentar a ação institucional denominada desmantelamento, por meio das unidades de registro debilidade de mecanismos. Observa-se aí a forma de ação que Lawrence e Suddaby (2006) designam desconexão de sanções: "[...] hoje a gente não tem nenhuma resolução, nenhum mecanismo que determine que ele [o usuário] vá primeiro à empresa, então ele vai poder [...]" (Depoimento de um dos entrevistados - ANTT). Os resultados das análises da entrevista feita na Ouvidoria da Antaq apresentaram o tipo de ação institucional denominado criação, por meio das unidades de registro estabelecimento de regras. Mais uma vez, observa-se a forma de ação que Lawrence e Suddaby (2006) chamam de determinação:

Como a parte de informática é terceirizada nas agências reguladoras, houve, hã... mudanças internas aí de contrato, de licitação de empresas e ficamos lutando aí até a empresa concluir esse trabalho, quando foi ano passado, em agosto, era para ser julho, quando foi em agosto, a gente concluiu, mesmo que sofrendo ainda ajustes para se consolidar [...] (Depoimento da atual [agosto de 2015] Ouvidora Interina - Antaq). 
Na fala a seguir, observa-se um exemplo de ação de criação através da unidade de registro construção de normas e práticas complementares. Nessa situação, a forma de ação é classificada como mimetismo:

E aí instaurou, averiguou, apurou, viu que realmente estava realmente irregular, pode até mudar a resolução, por exemplo, a 902 - está sendo alterada, está já em audiência para já modificar os pontos que estão assim em desacordo com a realidade, né, eu até tento fazer minhas contribuições (Depoimento da atual [agosto 2015] Ouvidora Interina - Antaq).

\section{Conclusões: aplicação do modelo teórico proposto para as ouvidorias pesquisadas}

Então, qual é a contribuição de Lawrence e Suddaby (2006) para o modelo teórico proposto? Esse se mostrou válido para a presente investigação? De fato, observaram-se evidências de ações institucionais de criação de instituições, especificamente na questão de estabelecimento de regras; particularmente, no caso da ANTT, evidências também de desmantelamento dessas; não foi notada evidência relevante, nas entrevistas, de conduta vinculada à manutenção de instituições nas ouvidorias pesquisadas.

Somente o modelo teórico original proposto por Mahoney e Thelen (2010) para descrever e explicar como o agente de mudança age não se mostrou suficiente - agente de mudança descrito pelos atores tem conduta reativa. Assim, se faz necessário migrar o conceito de agente de mudança para o de ator institucional (empreendedor político), proposto por Lawrence e Suddaby (2006), com o objetivo de explicar o processo de institucionalização das ouvidorias das agências estudadas. A contribuição de Lawrence e Suddaby (2006), inserindo o conceito de empreendedorismo institucional, abre um leque de possibilidades para inquirir atores interessados, que agem para influenciar contextos, tanto políticos como institucionais.

O resultado da análise nas duas agências pesquisadas demonstra, então, que existe um movimento para a institucionalização das suas ouvidorias, mediante o tipo de mudança institucional que Mahoney e Thelen (2010) denominam de conversão. Essa tipologia é ilustrada, como tratado anteriormente, a partir da ação de readequação de antigas instituições a novos propósitos, ou, ainda, da definição de novas finalidades para antigas estruturas de uma dada organização. Essas ações são definidas, ainda segundo os referidos autores, a partir do agente de mudança denominado oportunista. Essa tipologia é exemplificada pela imprecisão em que os atores encaram uma instituição, já que, para que esse agente aflore no processo de 
mudança institucional, deverão ser observadas lacunas entre regras e sua exposição ou interpretação, lacunas essas existentes devido à falta de previsão e análise crítica de suas consequências.

O tipo de agente de mudança denominado oportunista, ainda na concepção de Mahoney e Thelen (2010), tanto pode ou não procurar preservar a instituição, como ainda pode ou não seguir as regras da mesma. O ponto é que, a partir dos resultados da análise de conteúdo das entrevistas e dos documentos, observou-se que somente o modelo teórico original proposto pelos autores para descrever e explicar como o agente de mudança age não se mostrou suficiente, já que propõe um agente de mudança reativo, que só poderia surgir a partir de contextos políticos e características específicas das instituições. Não há espaço para análise de um possível empreendedorismo político na ação desses agentes. A contribuição de Lawrence e Suddaby (2006) acerca da ação institucional de atores para a criação, manutenção ou desmembramento de instituições dá suporte, assim, para apreender de forma mais robusta os resultados da pesquisa.

Esses resultados destacam que, predominantemente, o procedimento dos agentes de mudança pode ser explicado por meio da tipologia definida por Mahoney e Thelen (2010) como oportunistas, conduta essa notada nas duas ouvidorias pesquisadas. Como observado anteriormente, essa tipologia é descrita como aqueles que exploram as ambiguidades na interpretação ou aplicação das regras e acabam por refazer as regras existentes de forma diferente da intenção de seus formuladores. A respeito das características comuns em relação à ação institucional (LAWRENCE; SUDDABY, 2006), observa-se que os casos analisados demonstraram evidências de ações do tipo criação, especificamente na questão de estabelecimento de regras; foram encontradas evidências da forma de ação denominada determinação, definida como: agir para construção de sistemas de regras que conferem status ou identidade, ou ainda, definir limites de adesão, ou criar uma hierarquia de status dentro da área de atuação do ator; e nenhuma fala de ator demonstrou ações do tipo manutenção de instituições. Pode-se inferir desse fato específico que, sendo as ouvidorias públicas ainda um tipo de organização em consolidação, essa ação institucional não teria chances de acontecer. Em relação às características observadas em apenas uma situação, acerca da ação institucional, tem-se que, na Ouvidoria da ANTT, observouse a ação institucional de desmantelamento de instituições, por meio das formas de ação denominadas desconexão de sanções e enfraquecimento de pressupostos e crenças; e o resultado da entrevista feita na Ouvidoria da Antaq revelou uma forma de ação institucional de criação não percebida nos outros casos: o mimetismo.

Esta pesquisa empregou o conceito de instituições como regras formais ou informais que permitem o surgimento de uma estrutura nas interações entre indivíduos. A ideia foi investigar o processo de institucionalização das 
duas ouvidorias, ou seja, como esses setores se institucionalizam dentro das suas respectivas organizações, as agências reguladoras. No entanto, não foi a intenção desta pesquisa utilizar, por exemplo, o modelo de Tolbert e Zucker (1997) acerca dos estágios de institucionalização. Ao contrário, foi utilizada como modelo teórico proposto a teoria da mudança institucional de Mahoney e Thelen (2010), aliada às formas de ação institucional de Lawrence e Suddaby (2006). A aderência dessas teorias dá-se pelo fato de que, originalmente, a teoria de Mahoney e Thelen (2010) não explora possíveis ações de proatividade dos denominados agentes de mudança. Então, fez-se necessário complementar essa teoria com a contribuição de Lawrence e Suddaby (2006), que, inserindo o conceito de empreendedorismo institucional, abre um leque de possibilidades para inquirir, em suas próprias palavras, atores interessados, que agem para influenciar contextos, tanto políticos como institucionais. O resultado dessa análise comprova que, de fato, observam-se, no espaço de investigação proposto, ações proativas de indivíduos que compõem - ou compuseram - a equipe das respectivas ouvidorias pesquisadas.

A visão de estruturas formais e estáticas está associada com a percepção de passividade nos processos de institucionalização. Tal percepção pode estar errada, uma vez que algumas organizações e atores, em determinadas situações, precisam se conformar a mandatos institucionais e à limitação de recursos, o que pode não ocorrer de forma passiva (LAWRENCE; SUDDABY, 2006). A questão que se coloca é, então, considerando, de um lado, o peso que as instituições impõem sobre os agentes e, de outro, a necessidade de inovar práticas e estratégias, entender como os atores podem romper as amarras que os limitam e se organizarem para criar, manter ou desmembrar instituições.

Nesta pesquisa, acolhe-se a essência desse paradoxo e busca-se contribuir com o debate já existente na literatura, ao se apresentar um posicionamento diferente, seguindo as orientações de autores tais como Lawrence e Suddaby (2006), que alertam para a necessidade de se dar maior atenção aos trabalhos com cunho sociológico e etnográfico como pistas de reflexão. Esta pesquisa também busca destacar o desempenho de atores centrais (empreendedores institucionais) no processo de transformação organizacional de instituições em campos organizacionais em emergência ou em mudança. Considerando, então, que a institucionalização consiste no compartilhamento, por um grupo social, de um conjunto de ideias, normas, valores e sentimentos, estabelecendo assim uma instituição, pode-se definir o processo de institucionalização como originado na interação social, emergindo da dinâmica coletiva caracterizada pelas consciências individuais de seu desempenho na construção de instituições (FRUMKIN; KAPLAN, 2000). 
As duas ouvidorias das agências reguladoras pesquisadas detêm elementos em comum que merecem destaque na explicação acerca de seus processos de institucionalização. As duas demonstraram que o tipo de mudança institucional para tanto é definido como conversão (MAHONEY; THELEN, 2010), ou seja, os agentes de mudança não promovem, necessariamente, a alteração de regras e normas. Em vez disso, as regras são reinterpretadas em favor desses agentes. Isso acontece porque existe um espaço ambíguo entre a legislação (leis de criação e regimentos internos) referente às competências do ouvidor e de sua equipe e os recursos estruturais, financeiros e humanos, que são escassos. Essa situação provoca, ainda segundo Mahoney e Thelen (2010), o aparecimento do agente de mudança institucional denominado oportunista.

O que podemos inferir acerca dessas conclusões para explicar o processo de institucionalização? De fato, tem-se que as ouvidorias das agências reguladoras federais estão ainda se institucionalizando frente às suas respectivas agências. A mesma lei de criação das agências não influi para que ambas sejam institucionalizadas da mesma maneira. O que influencia? O desempenho de empreendedores institucionais - ouvidores, ex-ouvidores e equipe de servidores e assessores - quando encaram ante si um espaço de negociação para reinterpretação das regras atuais definidas pelos governos criadores dessas organizações. Esses agentes de mudança não estão interessados em manter instituições nas quais, no fundo, não depositam inteira confiança. Mas também não trabalham para desfazê-las e substituí-las, e, sim, (re)construí-las para que, de fato, os apoiem no desempenho de seus papéis.

\section{Referências bibliográficas}

APPolınáRIO, F. Dicionário de metodologia científica: um guia para a produção do conhecimento científico. São Paulo: Atlas, 2009.

Cellard, A. A análise documental. In: Poupart, J. et al. A pesquisa qualitativa: enfoques epistemológicos e metodológicos. Petrópolis: Vozes, 2008.

DIMAgGIO, P. J. Interest and agency in Institutional Theory. In: ZUCKER, L. G. (Ed.). Institutional patterns and organizations: culture and environment. Cambridge, MA: Ballinger, 1988. p. 3-20.

FRUMKIN, P.; KAPLAN, G. Institutional Theory and the micro-macro link. JobPaper, 2000. Disponível em: <http:carbon.cudenver.edu/ gkaplan/papers.htm>. Acesso em: 15 jun 2013.

BAumgartneR, F.; B. D. JONES. Agendas and Instability in American Politics. Chicago: University of Chicago Press, 1993.

LAWRENCE, T.; Suddaby, R. Institutions and institutional work. In: Clegg, S. R. et al. (Eds.). Handbook of organization studies. $2^{\text {nd }}$ Edition. London: Sage, 2006. p. 215-254. 
LÜDKE, M.; ANDRÉ, M. E. D. A. Pesquisa em educação: abordagens qualitativas. São Paulo: EPU, 1986.

MAHONEY, J.; THELEN, K. A theory of gradual institutional change. In: MAHONEY, J.; THELEN, K (Eds.). Explaining institutional change - ambiguity, agency and power. New York: Cambridge University Press, 2010. p. 1-37.

MARCH, J. Como as decisões realmente acontecem: princípios da tomada de decisões nas organizações. São Paulo: Leopardo, 2009.

OLIVER, C. Strategic responses to institutional processes. Academy of Management Review, v. 16, n. 1, p. 145-179, 1991.

The antecedents of deinstitutionalization. Organization Studies, v. 13, n. 4, p. 563-588, 1992.

PIERSON, P. Politics in time. Princeton: Princeton University Press, 2004.

STAKE, R. The art of case study research. London: Sage, 2000.

STREECK, W.; THELEN, K. Introduction: institutional change in advanced political economics. In: STREECK, W.; THELEN, K. (Eds.). Beyond continuity - institutional change in advanced political economics. Oxford: Oxford University Press, 2005. p. 1-39.

THELEN, K. How institutionalism evolves: insights from comparative historical analysis. In: MAHONEY, J.; RUESCHEMEYER, J. (Eds.). Comparative historical analysis in the Social Sciences. New York: Cambridge University Press, 2003. p. 208-240.

TOLBERT, P.; ZUCKER, L. The institutionalization of Institutional Theory. In: CLEGG, S.; HARDY, C.; NORD, W.R. (Orgs.). Handbook of organizational studies. London: Sage, 1997. p. $175-190$.

\section{Documentos Oficiais}

AgÊncia nacional de Trasnportes Aquaviários (AntAQ). Ouvidoria da Antaq (n.d.). Disponível em: http://www.antaq.gov.br/sistemas/Ouvidoria/Ouvidor.htm. Acesso em: 11 Ago. 2012.

AgÊncia nacional de TRAsnportes AquaviáRios (ANTAQ). Relatórios de Gestão (2003, 2010 e 2011). Disponível em: http://www.antaq.gov.br/Portal/. Acesso em: 11 Ago. 2012.

Agência nacional de Transportes Terrestres (ANTT). Ouvidoria da ANTT. (n.d.). Disponível em: http://www.antt.gov.br/Ouvidoria/Ouvidoria.asp. Acesso em: 11 Ago. 2012.

Agência nacional de Transportes TerRestres (ANTT). Carta de Serviços ao Cidadão (s.d.). Disponível em: <http://www.antt.gov.br/index.php/content/view/13003/ Carta_de_Servicos.html>. Acesso em: 27 de jan. 2013.

Agência nacional de TRAnsportes TerRestres (ANTT). Relatórios da Ouvidoria (semestral). Brasília: Agência Nacional de Transportes Terrestres. Disponível em: <http://www.antt.gov.br/index.php/content/view/6516/Relatorios.html > Acesso 27 de janeiro de 2013. 


\section{Luciana de Oliveira Miranda}

Possui Doutorado em Administração Pública pela Universidade de Brasília (UnB). Atualmente é professora da Faculdade UnB Planaltina e do Programa de Pós-Graduação em Gestão Pública do mesmo Campus. É pesquisadora do Centro de Estudos Avançados de Governo e Administração Pública (CEAG/UnB) e membro do Grupo de Pesquisa sobre Instituições e Políticas Públicas (GIPP/UnB). Contato: luolivmiranda@gmail.com

\section{Paulo Du Pin Calmon}

Possui doutorado em Políticas Públicas - University of Texas System, EUA. Atualmente é professor da Universidade de Brasília (UnB), Diretor do Instituto de Ciência Política (campus Darcy Ribeiro) e professor do Programa de PósGraduação em Ciência Política do mesmo campus. Pesquisador do Centro de Estudos Avançados de Governo e Administração Pública (CEAG/UnB) e Líder do Grupo de Pesquisa sobre Instituições e Políticas Públicas (GIPP/UnB). Contato: paulo.calmon@gmail.com 